\title{
СЕТЕВОЕ ТВОРЧЕСТВО КАК НОВЫЙ ТИП КУЛЬТУРЫ
}

\section{NETWORKED CREATIVITY AS A NEW TYPE OF CULTURE}

V. Skopa

Summary: Based on the studied material, the article attempts to reveal network creativity as a new type of culture. The theory of the information society, based on the realization that today we are dealing with a qualitatively new communicative environment, seems to be fundamental in the context of the problematics. Based on the concept of Three Waves by $E$. Toffler, post-industrial society by D. Bell, the fourth information revolution by M. McLuen and the information society by M. Castells, the key features of the culture of the new time are highlighted. It was determined that the variety and unlimited choice (viewing, studying, cognition), which the Internet offers today, have determined the clip-like culture of the information society.

Keywords: culture, post-industrial society, network creativity, modernization, content.

\author{
Скопа Виталий Александрович \\ Д.и.н., Алтайский государственный педагогический \\ университет, г. Барнаул \\ sverhtitan@rambler.ru
}

Аннотация: В статье на основе изученного материала предпринята попытка раскрыть сетевое творчество как новый тип культуры. Основополагающей в контексте проблематики представляется теория информационного общества, основанная на осознании того, что сегодня мы имеем дело с качественно новой коммуникативной средой. Опираясь на концепции Трех волн Э. Тоффлера, постиндустриального общества Д. Белла, четвертой информационной революции М. Маклуена и информационного общества М. Кастельса выделены ключевые признаки культуры нового времени. Определено, что разнообразие и неограниченность выбора (просмотр, изучение, познание), которые предлагает сегодня интернет, обусловили клиповость культуры информационного общества.

Ключевые слова: культура, постиндустриальное общество, сетевое творчество, модернизация, контент.
$\mathrm{M}$ етодологические поиски в культурологии имеют двойную актуальность. Во-первых, культурология является молодой, еще не канонизированной наукой, в которой только формируется методология познания, поэтому любая исследовательская попытка конкретизировать, адаптировать или расширить традиционный методологический аппарат вносит вклад в ее развитие. Во-вторых, сетевое творчество, которое стала предметом исследования, касается меняющегося пространства культуры, находится под неизбежным влиянием информационно-технологической парадигмы современного общества, а следовательно, требует новых методологических решений в ее исследовании.

Цель статьи - определить теоретико-методологические предпосылки исследования сетевого творчества в контексте формирования нового типа культуры.

Основополагающей в контексте проблематики представляется теория информационного общества, основанная на осознании того, что сегодня мы имеем дело с качественно новой коммуникативной средой, а коммуникация является стержнем человеческого бытия, меняются все его сферы, в том числе культура. Опираясь на концепции Трех волн Э. Тоффлера, постиндустриального общества Д. Белла, четвертой информационной революции М. Маклуена и информационного общества М. Кастельса, можно выделить первые ключевые признаки культуры нового времени $[1,6,9,10]$. Так, Э. Тоффлер в своей концепции определяет современную культуру как демасифицированную и клиповую [10]. «Элитарная - массовая - демассифицирована» - это тот путь, который прошла культура в соответствии с первой (аграрной), второй (индустриальной) и третьей (информационной) волн в контексте ее доступности [10, с. 374]. В качестве примера можно обратиться к музыкальному искусству. В период длительного господства сельскохозяйственной цивилизации, когда люди обычно жили в больших семьях, которые состояли из нескольких поколений, причем все они жили под одной крышей и работали вместе как производственная ячейка, производительность которой напрямую зависела от плодородия земли, плодовитости скота, природных явлений, музыка имела особое магически охранное значение, шла она от народа и перепевалась поколениями, ее можно было услышать во время работы (бытовая), праздников (календарнообрядовая и семейно-обрядовая), походов (чумацкая, бурлацкая), а следовательно сопровождала человека как в повседневности, так и во времена значимых событий, была не отдельным «концертным» явлением в жизни крестьян, а растворялась в нем [8]. Сельскохозяйственное общество Э. Тоффлер метко охарактеризовал как «производители для себя», сами производили сами и ели, и как мы видим на примере с музыкой, это касается не только продовольствия, но и культуры [10]. Второй вектор существования музыки в период Первой волны - элитарная. Это композиторская музыка, выполняется при так называемых дворах покровителей, перед зрителями с высоким интеллектуальным уровнем и образованности. Вторая волна знаменовалась становлением промышленного производства, раскололо общество на нуклеарные семьи, производителей и потребителей, 
ввело массовое образование и расстроило мощную систему средств массовой информации, затем создало все условия для эффективного массового управления рабочим классом [4].

В результате цивилизационного слома так же существенных изменений претерпел досуг, который потеряв связь с народными традициями, приобрел форму профессиональной организации массовых мероприятий, тем самым превратившись в индустрию, что полностью соответствовало духу эпохи. Так, возвращаясь к музыке, появились большие концертные залы, театры, в результате чего произошло смещение от камерных до симфонических форм. Музыкальные концерты стали доступными для широких слоев населения, билеты на которые можно было свободно приобрести в кассах города. Позже, с изобретением звукового и звукозаписывающего оборудования, а также с развитием средств массовой коммуникации, музыка, благодаря телевизионным экранам, радиоприемникам, магнитофон, получила новые трансляционные возможности, и зазвучала в каждом доме. Искусство стало продуктом массового потребления, поэтому наступила формация массовой культуры [2]. В период Третьей волны, символом которой стали сетевые технологии, разрушающие централизованный контроль над искусством, происходит демассификация потребителя культурных благ. Отныне музыка звучит для каждого персонально, в зависимости от индивидуальных предпочтений [10]. Тоффлер Э. по этому поводу отметил, что «все эти разработки имеют одну общую черту: они разделяют общую аудиторию на группы, и каждый новый сегмент увеличивает разнообразие нашей культуры» $[10$, с. 473].

В то же время, то разнообразие и неограниченность выбора, которые предлагает сегодня интернет, обусловили клиповость культуры информационного общества, что, с одной стороны, объясняется устремлениям производителей культурных благ быть замеченными, а с другой - попыткой потребителей охватить как можно больше интересного им контента [3]. Цифровые пиктограммы, стикеры в онлай-месенджерах, интернет-мемы, музыкальные клипы, короткие видеоролики на платформе You Tube и многое другое - это, по сути, артефакты сетевой культуры, адаптируют информацию для легкого и быстрого восприятия. Белл Д. в своей теории постиндустриального общества имеет рассуждения, что «старая концепция культуры базируется на преемственности, современная - на разнообразии; старой ценностью была традиция, современный идеал - синкретизм»[1, с. 292]. Этот тезис был сформулирован в 1973 году, однако впоследствии его значение только усиливалось. Сегодняшние сетевые технологии предложили альтернативную территорию для творческого эксперимента, в процессе которого смешиваются виды, стили, жанры, а в результате - рождается нечто новое, но значимое, поскольку представляет ценности текущей исторической эпохи. Маклуен М. определил культуру информационного общества как глобальную и мозаичную [9, с. 156].

Сегодня принцип глобализации обеспечивается фактическим отсутствием физических границ в сети интернет и сверхвысокой скоростью передачи информации в ней, что ученый объединил под термином «глобальная деревня», но по отношению к традиционным СМИ; а принцип мозаичности, в свою очередь, сформировался из-за специфики чтения электронной информации, то есть урывками через интервалы, переходя по ссылкам, в отличие от чтения книг, которое обеспечивает последовательное восприятие информации, а следовательно способствует формированию линейного мышления [9].

Развивая идеи теории информационного общества, М. Кастельс так же рассматривает современную культуру как глобализованную, охарактеризовав ее как мультикультурной системой координат, говоря о широкой культурной дифференциации технологических инноваций [5, с. 217]. Будучи профессором университета в американском штате Калифорния, который является главным центром разработки информационных технологий, М. Кастельс смог одним из первых наблюдать формирование информационно-технологической парадигмы и описать трансформацию общества под ее влиянием. В результате в его работах мы находим первые зафиксированные признаки новой коммуникативной платформы, важнейшим среди которых ученый определяет «охват в своей сфере большинства видов культурных проявлений во всем их разнообразии. От худших к лучшим, от самых элитных до самых популярных, сочетаются в этой цифровой вселенной, что связывает супертексты прошлые, настоящие и будущие проявления коммуникативной мысли. Таким образом они развивают новую символическую среду. Делают виртуальность нашей реальностью» [6, с. 461]. В своих трудах М. Кастельс очертил переход современного общества от «галактики Гутенберга» к «галактики интернет» и первым выделил понятие сетевой культуры. «Это культура, построенная на технократической вере в прогресс человечества под влиянием техники, принята сообществом хакеров, развивается на основе свободной и открытого технического творчества, внедрена в виртуальные сети, имеет целью построение нового общества, и творении новой экономики» [5, с. 283].

В теории информационного общества, в условиях глобализации, сформировалась главная идея о том, что средства массой культуры позволяют выделить устную, письменную, аудиовизуальную и сетевую цивилизации. Появляясь, новые медиа постепенно меняют нашу жизнь [7]. Так, Э. Тоффлер выделяет появление новой возможности самостоятельных манипуляций в информационном пространстве, хотя и очень простых. Прежде всего ученый определяет видеоигры, которые превратили экран из информационного средства в информационно- 
коммуникативное поле. «Эта разработка представляет собой волну социального научения, это предварительная тренировка, которая готовит нас к жизни в электронном мире. Благодаря этому нехитрому прибору миллионы людей учатся играть с телевизором, отвечать ему, взаимодействовать с ним» [10]. Следовательно, можно говорить о том, что видеоигры заложили основу потребительского просьюмеризма, который позже стал одной из определяющих характеристик нового типа культуры. Следующими судьбоносными разработками стали компьютер и всемирная система компьютерных сетей под общеизвестным названием интернет. О компьютере Тоффлер пишет: «Этими умными машинами уже пользуются в самых разных целях: от оформления семейных счетов по контролю расходов электроэнергии в доме. С ними играют, в них сохраняют кулинарные рецепты, они напоминают своим владельцам о запланированных встречах и служат «интеллектуальными» печатными машинками» [10, с. 512]. В этом тезисе автор записал лишь малую часть потенциальных возможностей компьютеров. С их появлением, а также с появлением интернета практика потребительского просьюмеризма расширилась, человек получил доступ к собственному созданию контента, к свободному выражению собственного мнения, к наполнению культуры собственными произведениями.

В таком случае, можно отметить, что по теории об информационном обществе рождается новое исследовательское направление - медиа-археология. Высокий технологический уровень развития современных медиа, по сравнению с прошлой эпохой, а также их всеобъемлющая популярность, безусловно, не могли остаться без внимания ученых самых разных специальностей, что привело к появлению активного междисциплинарного дискурса о них.

Медиа-археология, истоки которой мы наблюдаем в работах М. Маклуена, позже у Э. Тоффлера и М. Кастельса, а также французского философа и культуролога М. Фуко, отмечено, что «археология означает «раскопки» предмета исследования до архаического уровня, который позволяет познание и способ бытия того, что предстоит познать» [11, с. 185]. Чтобы получить ответ на вопрос о том, что предвещало приход современной медиа-цивилизации, заняла почетное место в методологии исследования проблема влияния современных информационно-коммуникативных технологий на формирование нового типа культуры, ведь - это «взгляд на медиакультуру не только через призму прошлого, настоящего и будущего, но и во взаимосвязи всех времен. Это способ связать вместе все эти временные пласты и объяснить их друг через друга» [3]. В целом, выделяя способ исследования культуры путем совершенного изучения медиа, можно говорить о формировании культуротехничного подхода в культурологии. Так, в трудах профессора Калифорнийского университета Е. Хухтамо мы находим расширенную культурную концептуализацию термина «медиа», он описывает ее в качестве «нефиксированных объектов, у которых нет определенных границ. Они сконструированы комплексами желаний, верований и процедур, встроены в сложные культурные коды коммуникации» [12].

Жилина А.В. в своем анализе медиа-теории относительно теории Э. Хухтамо метко замечает, что таким образом ученый рассматривает не сами медиа и условия их существования, а как «дополнительные» культурные медиации [4]. Эту идею (топосив) Хухтамо позаимствовал из риторики классической античности. Они были местами для хранения направлений мысли, систематически организованными формулами, которые служили практической цели, а именно составлению речей. Когда классическая риторика постепенно потеряла свое первоначальное значение и цель, формулы проникли в литературные жанры. Превратившись в клише, которые можно использовать в любой литературной форме, они распространились на все сферы жизни, к которым имеет отношение литература и которым она придает форму. Итак, топики можно рассматривать как формулы, от стилистической до аллегорической, они составляют «строительные блоки» культурный традиций, а, следовательно, являются идеологическими конструкциями [12]. Современные медиа находятся в тесной связи с человеком. Вероятно, эту связь можно охарактеризовать как самый прочный за всю историю человечества. Медиа-устройства и технологии всегда находятся под рукой. Мы проверяем свои мессенджеры, почту и профили в социальных сетях каждые 12 минут, проводим время в сети в течение 24 часов в неделю, вдвое больше чем 10 лет назад [6]. Сейчас новые медиа образуют киберпространство культуры, активно вмешиваются в реальную жизнь, где происходит кросскультурный диалог, в контексте которого возникают новые культурные универсалии, единые для всей современной культуры. В таком случае сетевые артефакты представляют собой существенный семиотический комплекс, исследования которого приближает нас к научной констатации культуры нового типа.

Если подвести итог, то можно отметить, что представлена попытка привлечь сетевое творчество, в том числе, герменевтического дискурса, в рамках которого раскрывается ее интерпретационный потенциал. Интерпретация произведения, будь то интернет-мем, видеоролик на You Tube или фотография в Instagram не будет объективной, если оставить без внимания культуру, и наоборот - невозможно сформировать представление о культуре, не ознакомившись с ее творчеством. Такое положение отражает сущность герменевтического круга: «понимание текста невозможно без понимания контекста, а понимание контекста невозможно без понимания текста» [8]. 


\section{ЛИТЕРАТУРА}

1. Белл Д. Грядущее постиндустриальное общество. Опыт социального прогнозирования / пер. с англ. В. Л. Иноземцева. М., 2004.788 с.

2. Крючком А. «Археология знания»: к проблеме становления философско-исторических взглядов М. Фуко. Философия и политология в контексте современной культуры. 2012. Вып. 4 (2). С. 200-207.

3. Герман И. Эволюция технологий: Эркки Хухтамо о том, чем занимаются археологи медиа. URL: https://theoryandpractice.ru/posts/10145-arkheologiyamedia (дата обращения: 20.04.2021).

4. Жилина А.В. В преимуществах материалистического подхода в теории медиа // Философский журнал. 2017. № 3. Т. 10. С. 93-111.

5. Кастельс М. Галактика Интернет / пер. с англ. А. Матвеева под ред. В. Харитонова. Екатеринбург, 2004. 328 с.

6. Кастельс М. Информационная эпоха: экономика, общество и культура / пер. с англ. под науч. ред. 0.И. Шкаратана. М., 2000. 608 с.

7. Киттлер Ф. Медиа философии, философия медиа / пер. с нем. И. Инишева // Логос. 2015. Т. 25. № 2 (104). С. 173-188.

8. Колесник А.С. Культурологическая герменевтика и диалог контекстов // Культура и современность. 2014. № 1. С. 24-30.

9. Мак-Люэн М. Галактика Гутенберга: сотворение человека печатной культуры / пер. с англ. А. Юдина. Киев, 2004. 432 с.

10. Тоффлер Э. Третья волна / пер. с англ. Л. Бурмистрова, К.Л. Татаринова, К. Бурмистров, З. А. Заритовская. М., 2010. 800 с.

11. Фуко М. Археология знания / пер. с фр. Раковая М. Б. СПб., 2004. 416 с.

12. Huhtamo E. From Kaleidoscomaniac to Cybernerd: Notes Toward an Archaeology of the Media. Leonardo. 1997. No. 3. Vol. 30. Pp. $221-224$.

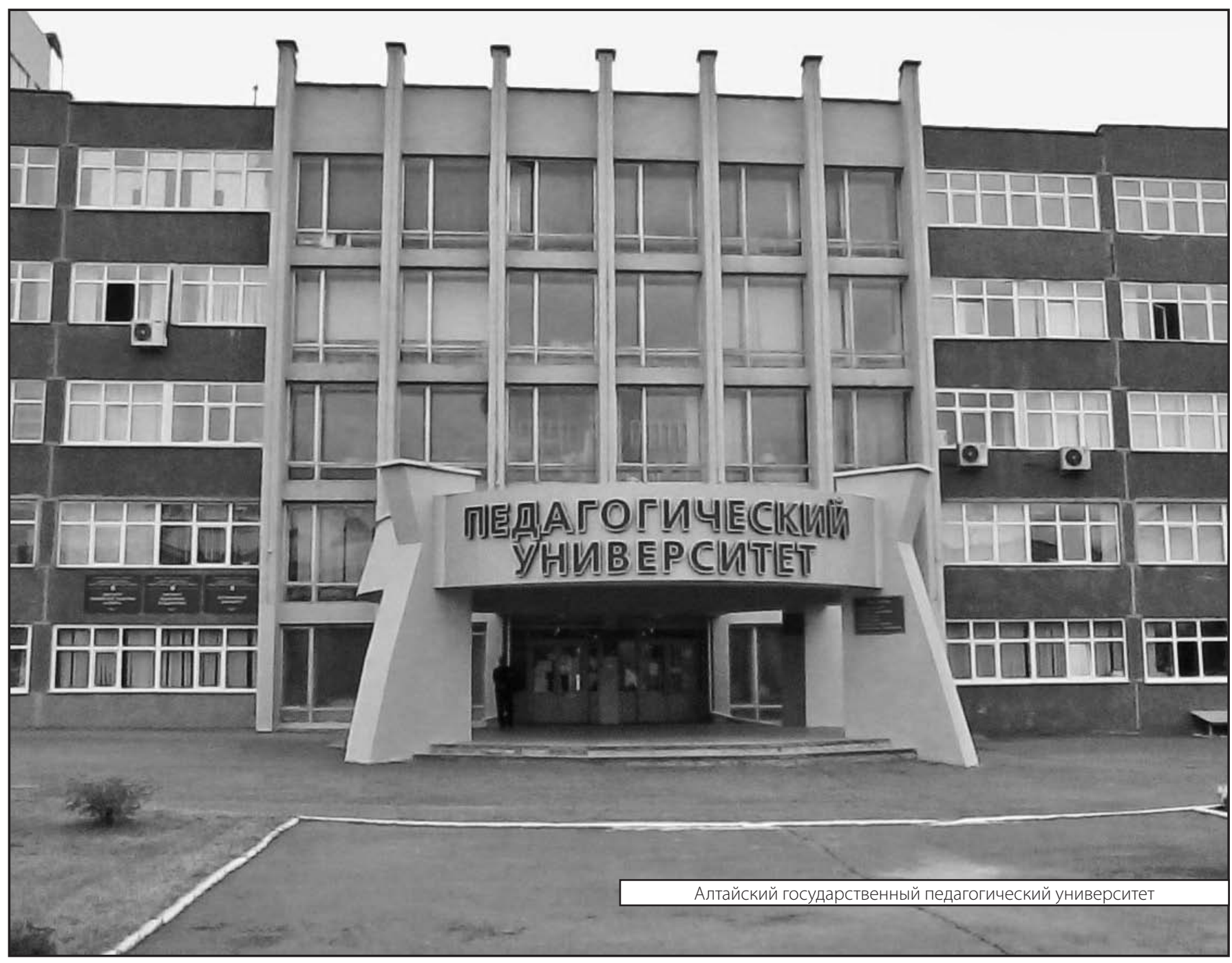

